\title{
SciDoC
}

Infer, Interpret \& Inspire Science

\author{
International Journal of Dentistry and Oral Science (IJDOS) \\ ISSN: $2377-8075$
}

\section{Assessment of Efficacy of Various Root Canal Irrigants using SEM Evaluation}

Research Article

Gonapa Prasanthi ${ }^{1}$, Gondi Durga Bhavani ${ }^{1 *}$, Sathyanarayana Reddy Poreddy ${ }^{1}$, R Tejasree Rathod ${ }^{1}$

${ }^{1}$ Assistant Professor, Department of Conservative Dentistry \& Endodontics, Government Dental College and Hospital, Kadapa, Andra Pradesh, India.

\section{Abstract}

Introduction: The main objective of endodontic procedure is to eliminate all vital/necrotic tissue, micro-organisms, and microbial by-products from the root canal system.

Aim: The study was done to evaluate the efficacy of various root canal irrigants using scanning electron microscope (SEM) Materials and Methods: Forty maxillary human premolar teeth were divided into 4 groups with 10 samples in each groups; group A: MTAD, group B: chlorhexidne, group C: Ozone water and group D: as control group irrigated with 5.25\% sodium hypochlorite. The samples were sectioned after irrigation with each irrigating solution and observed under the scanning electron microscope (SEM) at coronal, middle and apical thirds of root canal. The SEM was evaluated and scored for residual debris and smear layer. Then information was tabulated and statistically evaluated.

Results: The tested root canal irrigants MTAD, Ozone water, Chlorhexidine and Sodium hypochlorite has removed debris and smear layer at coronal, middle and apical third of canals.

Conclusion: MTAD was more effective in reducing the both debris and smear layer compared to other tested products.

Keywords: Chlorhexidine; Irrigants; MTAD; Ozone Water; Root Canal; Smear Layer.

\section{Introduction}

The main objective of endodontic procedure is to eliminate all vital/necrotic tissue, micro-organisms, and microbial by-products from the root canal system and to encourage periapical tissue healing.[1] Endodontic instrumentation using both hand and rotary instruments produces organic and inorganic debris that are embedded within a layer of amorphous tissue. Smear layer presence has demonstrated to be harmful because it avoids the penetration of intracanal medicaments, irrigants, and also the obturating materials. [2] Moreover, the smear layer has the potential to protect bacteria within the dentinal tubules. [3] Thus it is necessary to eliminate this debris and smear layer during endodontic procedure. To accomplish this, chemo-mechanical root canal preparation should be done with canal enlargement along with thorough irrigation using bactericidal irrigants. [2, 4-6] Various root canal irrigants are in use to eliminate smear layer such as, sodium hypochlorite, chlorhexidine, EDTA, MTAD, ozone water and several herbal irrigants were tried with some benefits.[7]
Torabinejad et al. introduced MTAD as an alternative irrigant of EDTA to remove the smear layer.[8] It has a combined chelating and antibacterial properties. Prior to use MTAD is mixed as a powder and liquid.[7] MTAD is a Mixture of a Tetracycline isomer, an Acetic acid, and Tween 80 Detergent. Before obturation, MTAD was intended to be used as a final root canal irrigant. MTAD is efficient in eliminating the smear layer thought the root canal length and in removing inorganic and organic debris. [9, 10] Ozone is a chemical compound made up of 3 oxygen atoms $\left(\mathrm{O}_{3}\right)$, a higher energetic form compared to normal atmospheric oxygen (O2). Ozone is a very powerful bactericidal agent that can kill microorganisms effectively. It is an unstable gas, capable of oxidizing any biological entity. It was reported that ozone at low concentration of $0.1 \mathrm{ppm}$, is sufficient to inactivate bacterial cells including their spores. It is available naturally in air and can be simply created with ozone generator. When introduced in water, ozone dissolves rapidly and dissociates rather quickly.[7, 9]

Chlorhexidine is used comprehensively in periodontal treatment due to its antimicrobial property against Gram-negative and Gram-positive microorganisms. It is a comparatively non-toxic,

\footnotetext{
*Corresponding Author:

Gondi Durga Bhavani,

Assistant Professor, Department of Conservative Dentistry \& Endodontics, Government Dental College and Hospital, Kadapa, Andra Pradesh, India.

E-mail: durgabhavanimds@gmail.com
}

Received: May 09, 2021

Accepted: July 22, 2021

Published: August 14, 2021

Citation: Gonapa Prasanthi, Gondi Durga Bhavani, Sathyanaravana Reddy Poreddy, R Tejasree Rathod. Assessment of Efficacy of Various Root Canal Irrigants using SEM Evaluation. Int J Dentistry Oral Sci. 2021;8(8):3666-3669.doi: http://dx.doi.org/10.19070/2377-8075-21000750

Copyright: Gondi Durga Bhavani ${ }^{\circ} 2021$. This is an open-access article distributed under the terms of the Creative Commons Attribution License, which permits unrestricted use, distribution and reproduction in any medium, provided the original author and source are credited. 
broad spectrum antimicrobial agent that offers remaining action with less probablity for adverse effects, thus offering a clinical advantage over sodium hypochlorite. [11] Unlike $\mathrm{NaOCl}$, chlorhexidine lacks a tissue-dissolving property.[5]

Sodium hypochlorite $(\mathrm{NaOCl})$ is the most commonly used irrigating solution. It is generally used in concentrations ranging from $0.5 \%$ to $6 \%$. $[9,11]$ It is an antibacterial agent, able to dissolve necrotic and vital pulp tissue, the organic components of dentin as well as biofilm. The antibacterial efficiency and tissue dissolution capability of aqueous hypochlorite is a function of its concentration, and so is its toxicity. $\mathrm{HOCl}$ exerts its effects by oxidizing sulfhydryl groups within bacterial enzyme systems. It is a potential microbial agent, killing most bacteria instantly on direct contact. $[7,10]$

There is no reported comparative studies related to MTAD, Ozone water, Chlorhexidine irrigating solution. Hence the purpose of this in vitro study was to evaluate the efficacy of MTAD, Ozone water, Chlorhexidine irritants solution over Sodium hypochlorite $(\mathrm{NaOCl})$.

\section{Materials And Method}

Forty maxillary human premolar teeth indicated for orthodontic extraction were selected and were divided into 4 groups with 10 samples in each groups; group A: MTAD, group B: chlorhexidne, group C: Ozone and group D: control group irrigated with 5.25\% sodium hypochlorite.

The selected teeth were decoronated using water-cooled double-sided diamond disc. In decoronated samples, working length was determined by inserting the \# $10 \mathrm{~K}$ file into the root canal. Each canal was shaped by crown down technique using the Protaper rotary system with X Smart; Endodontic Torque Control Motor (Dentsply, MalliferBallaigus, Switzerland). Instrumentation was done by sequential use of files in the order S1-S2 followed by apical preparation till pro taper size F4.

Debris is defined as "dentine chips, pulp remnants, and particles loosely attached on the root canal wall".4

- Score 1 - clean root canal wall, with few debris particles

- Score 2 - few small agglomeration of debris
- Score 3- many agglomerations of debris covering $<50 \%$ of the root canal wall

- Score 4 - more than $50 \%$ of root canal wall covered by debris

- Score 5 - complete or nearly complete root canal wall covered by debris.

Smear layer is defined as a "surface film of debris retained on the dentin or other surfaces after instrumentation with either rotary instruments or endodontic file, consisting of dentine particles, remnants of the vital or necrotic pulp tissue, bacterial components and retained irrigant”. [4]

- Score 1 - no smear layer, open dentinal tubules

- Score 2 - small amount of smear layer covering the root canal wall, only a few dentinal tubuli open

- Score 3 - homogeneous smear layer covering the root canal wall, only a few dentinal

tubuli open

- Score 4 - complete root canal wall covered by a homogeneous smear layer, no open

dentinal tubuli

- Score 5 - heavy, nonhomogeneous smear layer covering the complete root canal wall.

The debris a smear layer scoring procedure was performed by two different evaluators. After irrigation with respective solution, the samples were then sectioned and observed under the scanning electron microscope (SEM) at coronal, middle and apical thirds of root canal. The SEM was evaluated and scored for residual debris and smear layer. The results were then statistically analyzed using the ANOVA.

\section{Results}

Table 1 indicates mean residual debris and smear layer scores of MTAD, Ozone water, Chlorhexidine and Sodium hypochlorite root canal irrigants at coronal, middle and apical third of canals. It was found that MTAD has reduced the both debris and smear layer effectively compared to other tested products.

\section{Discussion}

In endodontic treatment, cleaning and shaping of the root canals is one of the main important phases. It has been stated, that

Table 1. Mean residual debris and smear layer scores.

\begin{tabular}{|c|c|c|c|}
\hline & \multicolumn{3}{|c|}{ Mean+_SD } \\
\hline Groups & Coronal & Middle & Apical \\
\hline Residual debris & \multicolumn{3}{|}{} \\
\hline MTAD & $1.01 \pm 0.21$ & $1.21 \pm 0.61$ & $1.32 \pm 0.15$ \\
\hline Ozone water & $1.41 \pm 0.54$ & $1.51 \pm 0.12$ & $1.72 \pm 0.41$ \\
\hline Chlorhexidine & $1.24 \pm 0.31$ & $1.33 \pm 0.14$ & $1.52 \pm 0.86$ \\
\hline Sodium hypochlorite & $1.04 \pm 0.01$ & $1.23 \pm 0.41$ & $1.38 \pm 0.34$ \\
\hline Smear layer & \multicolumn{3}{|}{} \\
\hline MTAD & $1.04 \pm 0.13$ & $1.14 \pm 0.45$ & $2.03 \pm 0.55$ \\
\hline Ozone water & $1.28 \pm 0.26$ & $2.15 \pm 0.74$ & $2.65 \pm 0.34$ \\
\hline Chlorhexidine & $1.26 \pm 0.76$ & $1.85 \pm 0.24$ & $2.12 \pm 0.87$ \\
\hline Sodium hypochlorite & $1.06 \pm 0.67$ & $1.47 \pm 0.56$ & $2.16 \pm 0.83$ \\
\hline
\end{tabular}


the smear material is made up of two layers: a superficial smear layer and a second layer that is packed into the dentinal tubules. The loosely adherent smear layer can harbor bacteria and give way for entry for leakage structure and hence it should be completely eliminated from the root canal wall. [2] Any material left between the canal wall and the root canal filling may prevent intimate adaptation between the two and may provide a space for bacterial leakage and bacterial proliferation. [4] Despite a variety of irrigating solutions available today, the search for an ideal root canal irrigant is a never-ending problem because of the dentine substrate, smear layer, [2] The apical third of the root canal is the most difficult portion to clean possibly because of its narrower dimension. Irrigation plays a major role in successful debridement and disinfection. It has been observed that, MTAD is effective in eliminating resistant micro-organisms and providing sustained antimicrobial activity. [3]

The present in vitro SEM study was done to ealaute the efficacy of MTAD, Ozone water, Chlorhexidine irritants solution over Sodium hypochlorite $(\mathrm{NaOCl})$ root canal irrigating solutions.

Singh et al, evaluated the 3 types of root canal irrigation systems, i.e., syringe, sonic, and ultrasonic. They observed, smear layer and debris removal at coronal third was considerably improved in comparison to apical third. At apical one-third, passive ultrasonic performed significantly better than both sonic and syringe irrigation.[2] Qiang Li et al, assessed the 4 irrigation protocols in smear layer removal and bacterial inhibition in root canal systems. They concluded that Passive ultrasonic irrigation (PUI) seems to be best infection control ability in root canal systems. 1 Rathakrishnan et al, evaluated an innovative Irrigant on smear layer removal. They stated that, Oxum the commercially available super-oxidized water seems to be equally efficient in smear layer removal with less erosion when comparision to EDTA.[2]

Paul et al, estimated the various irrigants under SEM. They concluded that, all the test irrigants including MTAD worked well in the middle and cervical third, whereas MTAD showed excellent results in the apical third as compared to the other groups. [3] The results are similar to our findings. Dagna et al, compare in vitro, by MTT assay, the antimicrobial efficacy of Niclor $5(5 \% \mathrm{NaOCl}$ solution), Cloreximid ( $0.2 \%$ chlorhexidine and $0.2 \%$ cetrimide solution), 3\% hydrogen peroxide and 17\% EDTA against two microorganisms related with primary endodontic infections. The great $\neg$ est antimicrobial effects were observed in groups treated with $5 \% \mathrm{NaOCl}$ and $17 \%$ EDTA. [5]

Letizia Borzini et al, assessed the literature on the chemotherapeutic agent and plant extracts as root canal irrigants and their effect on Enterococcus faecalis. They concluded that phytotherapic substances, could be a potential alternative to $\mathrm{NaOCl}$. [10] Bhandi et al, done a qualitative analysis of the published literature for assessing silver nanoparticles as root canal irrigants from PubMed, SCOPUS, Web of Science, and Embase databases search. They concluded that Silver nanoparticles have the potential to be used as endodontic irrigants, although their efficacy depends on particle size.[11] Giardino et al. assessed the $5.25 \% \mathrm{NaOCl}$ and MTAD (mixture of doxycycline, citric acid, and a detergentTween 80 ) and found that only $5.25 \% \mathrm{NaOCl}$ can successfully remove the E. faecalis biofilm.[12] The results are in contrast to our findings. Arun and Shenoy assessed the conventional and passive ultrasonic irrigation with sodium hypochlorite against three endodontic pathogens. They concluded that ultrasonic agitation of an irrigant proves to be a promising option to achieve significant bacterial reduction and thus achieves reliable and predictable endodontic success. [6]

Hariharan et al, determined the effectiveness of various root canal irrigants in removing the smear layer in primary teeth root canals. They found greater effectiveness of $6 \%$ citric acid than the other tested irrigants in removing the smear layer in deciduous teeth root canals. There was least smear removal efficacy in chlorhexidine group compared to other groups.[13]

Chaudhari et al, assessed the antimicrobial efficacy of Silver Diamine Fluoride (SDF), Sodium Hypochlorite (NaOCl), Bioactive Glass Nanoparticles (BAGNP) and Chitosan Nanoparticles (CNPs) as root canal irrigants against the bacterial strain of Enterococcus Faecalis (E. faecalis). They concluded that sodium Hypochlorite was the most effective root canal irrigant followed by SDF and Bioactive Glass Nanoparticle whereas Chitosan Nanoparticles was the least efficacious in comparision to the rest against Enterococcus Faecalis.[14]

Ruksakiet et al, from systematic review and meta-analysis on antimicrobial efficacy of chlorhexidine and sodium hypochlorite in root canal disinfection and concluded that both $\mathrm{CHX}$ and $\mathrm{NaOCl}$ irrigation can reduce bacterial infections without any significant difference in antimicrobial efficacy between them.[15] Nagaveni et al, assessed the antimicrobial efficacy of chlorhexidine and herbal root canal irrigant Aloe vera against Enterococcus faecalis. They concluded that Aloe vera is less effective as a root canal irrigants compared to chlorhexidine.[16]

Dunavant et al, evaluated the endodontic Irrigants against Enterococcus faecalis Biofilms. They concluded that, both $1 \% \mathrm{NaOCl}$ and $6 \% \mathrm{NaOCl}$ were more efficient in eliminating E. faecalis biofilm than the other solutions tested. [17] Spratt et al, evaluated the bactericidal effect of four antimicrobial agents against singlespecies biofilms derived from a range of root canal isolates. None of the agents were efficient against F. nucleatum after 15 minbut $\mathrm{NaOCl}$, iodine and chlorhexidine were all effective after $1 \mathrm{~h}$. Colloidal silver was generally ineffective. [18]

It was observed form the present study that MTAD is effective in removing debris and smears layer compared to other test agents. The draw of the study was. Lesser sample size and the study were in vitro. Further studies are needed to evaluate the efficacy of root canal agents on larger samples size with in vivo evaluation.

\section{Conclusion}

It is concluded from the present study that, all the tested irrigants showed effectiveness in removing root canal debris and smear layer but MTAD was more effective compared to other test agents.

\section{References}

[1]. Li Q, Zhang Q, Zou X, Yue L. Evaluation of four final irrigation protocols for cleaning root canal walls. Int. J. Oral Sci. 2020 Oct 19;12(29):1-6.

[2]. Rathakrishnan M, Sukumaran VG, Subbiya A. To Evaluate the Efficacy of an Innovative Irrigant on Smear Layer Removal - SEM Analysis. J Clin Diagn Res. 2016 Apr;10(4):ZC104-6.Pubmed PMID: 27190941

[3]. Paul ML, Mazumdar D, Niyogi A, Baranwal AK. Comparative evaluation 
of the efficacy of different irrigants including MTAD under SEM. J Conserv Dent. 2013 Jul;16(4):336-41.Pubmed PMID: 23956537.

[4]. Singh R, Nikhil V, Jaiswal S, Gupta S, Raj S, Arora R. A comparative evaluation of the efficacy of activated irrigation protocol on root canal debridement-A scanning electron microscopic study. Endodontology. 2020 Jan 1;32(1):26-32.

[5]. Dagna A, Arciola CR, Florindi F, Scribante A, Saino E, Visai L, et al. In vitro evaluation of antimicrobial efficacy of endodontic irrigants. Int J Artif Organs. 2011 Sep;34(9):914-9.

[6]. Arun J, Shenoy A. Comparative evaluation of efficacy of conventional and passive ultrasonic irrigation with sodium hypochlorite against three endodontic pathogens: An in vitro study. Int J Oral Health Sci. 2017 Jul $1 ; 7(2): 86-92$.

[7]. Gusiyska A, Gyulbenkiyan E VR, Dyulgerova E, Mironova J. Effective root canal irrigation-a key factor of endodontic treatment-review of the literature. Int J Recent Sci Res. 2016;7(4):9962-70.

[8]. Torabinejad M, Cho Y, Khademi AA, Bakland LK, Shabahang S. The effect of various concentrations of sodium hypochlorite on the ability of MTAD to remove the smear layer. J Endod. 2003 Apr 1;29(4):233-9.

[9]. Jaju S, Jaju PP. Newer root canal irrigants in horizon: a review. Int J Dent. 2011;2011:851359.Pubmed PMID: 22190936.

[10]. Borzini L, Condò R, De Dominicis P, Casaglia A, Cerroni L. Root canal irrigation: Chemical agents and plant extracts against Enterococcus faecalis. Open Dent. J. 2016;10:692-703.

[11]. Bhandi S, Mehta D, Mashyakhy M, Chohan H, Testarelli L, Thomas J, et al. Antimicrobial Efficacy of Silver Nanoparticles as Root Canal Irrigant's: A Systematic Review. J Clin Med. 2021;10(1152):1-11.Pubmed PMID: 33801820 .
[12]. Giardino L, Ambu E, Savoldi E, Rimondini R, Cassanelli C, Debbia EA. Comparative evaluation of antimicrobial efficacy of sodium hypochlorite, MTAD, and Tetraclean against Enterococcus faecalis biofilm. J Endod. 2007 Jul;33(7):852-5.Pubmed PMID: 17804328

[13]. Hariharan VS, Nandlal B, Srilatha KT. Efficacy of various root canal irrigants on removal of smear layer in the primary root canals after hand instrumentation: a scanning electron microscopy study. J Indian Soc Pedod Prev Dent. 2010 Oct 1;28(4):271-277.

[14]. CHAUDHARI DV, SHASHIKIRAN N, MAURYA A, GUGWAD S, GAONKAR N, TAUR S, et al. Comparative Evaluation of Antimicrobial Efficacy of Sodium Hypochlorite, Silver Diamine Fluoride Fluoride, Chitosan and Bioactive Glass Nanoparticles as Root Canal Irrigants against the Bacterial Strain of Enterococcus Faecalis-An In Vitro Study. J Clin Diagn Res. 2020 May 1;14(5) ): ZC22-ZC26.

[15]. Ruksakiet K, Hanák L, Farkas N, Hegyi P, Sadaeng W, Czumbel LM, et al. Antimicrobial efficacy of chlorhexidine and sodium hypochlorite in root canal disinfection: a systematic review and meta-analysis of randomized controlled trials. J. Endod. 2020 Aug 1;46(8):1033-41.

[16]. Nagaveni NB, Khan M, Poornima P. Comparative Evaluation of Antimicrobial Efficacy of Chlorhexidine and Herbal Root Canal Irrigant Aloe vera against Enterococcus faecalis: An in vitro Study. CODS J. Dent., July-December 2016;8(2):70-73

[17]. Dunavant TR, Regan JD, Glickman GN, Solomon ES, Honeyman AL. Comparative evaluation of endodontic irrigants against Enterococcus faecalis biofilms. J. Endod. 2006 Jun 1;32(6):527-31.

[18]. Spratt DA, Pratten J, Wilson M, Gulabivala K. An in vitro evaluation of the antimicrobial efficacy of irrigants on biofilms of root canal isolates. Int. Endod. J. 2001 Jun;34(4):300-7. 